\title{
Role Of Fruit Juice Of Watermelon (Citrullus Vulgaris Rubrum) Handling In Hypertension In Work Area Health Center Cempaka Banjarmasin
}

\author{
Dini Rahmayani ${ }^{1}$, Ir.Nordiansyah Firahmi ${ }^{2}$, Deni okvianti ${ }^{3}$ \\ \{ns.dinirahmayani@gmail.com,nordiansyah@gmail.com,deniokvianti@gmail.com\} \\ Nursing Study Program of Health Faculty Universitas Sari Mulia, Banjarmasin, Indonesia ${ }^{13}$ \\ Universitas Islam Kalimantan, Banjarmasin, Indonesia ${ }^{2}$ \\ *ns.dinirahmayani@gmail.com
}

\begin{abstract}
Hypertension is blood pressure above the normally figure of $120 \mathrm{mmHg}$ systole and diastole $80 \mathrm{mmHg}$. If no tackles Hypertension disease will lead to death. The watermelon is one of the therapies that can be used for patients with hypertension. The objective of this study is to analyze the role of fruit juice of watermelon in the treatment of hypertension in Puskesmas Cempaka Banjarmasin. The design of the study using a descriptive study sampling technique using the side with the total number of 18 people who will do the research. The results showed that the average systolic blood pressure before being given $146.11 \mathrm{mmHg}$, an average of $92.22 \mathrm{~mm} \mathrm{Hg}$ diastolic blood pressure. The results R2 -2.569 systolic blood pressure and blood pressure results Diastole -0.511 $\mathrm{R} 2$ and the result average blood pressure after systole given watermelon juice 121.66 $\mathrm{mmHg}$ and $83.89 \mathrm{mmHg}$ Diastole blood pressure. The role in watermelon fruit juice can lower high blood pressure (hypertension) and can stabilize blood pressure remained stable
\end{abstract}

Keywords: hypertension disease, watermelon.

\section{Introduction}

Hypertension is an increase in blood pressure above the normal systolic rate of 120 $\mathrm{mmHg}$ and diastole of $80 \mathrm{mmHg}[1]$. Hypertension has long been known that as one of the health problems that occur because it can be caused by unhealthy lifestyles, such as diet, smoking and lack of exercise[2].

According to WHO (2013) states that the prevalence of hypertension in the World in 2013, namely the population aged> 18 years reached 1 billion people, the highest country suffering from hypertension in Africa (46\%) while the lowest prevalence in America (35\%) Overall, the country high-income countries have lower prevalence $(35 \%)$ than low and middle income groups $(40 \%)$. Researchers claim that high blood pressure nearly 9.4 million deaths 
from cardiovascular disease each year. Blood pressure can cause heart disease and stroke, of the total 7.5 million people died ${ }^{[3]}$. According to Basic Health Research data [4]in Indonesia at the age of $\geq 18$ years suffering from hypertension $31.7 \%$ and There was a decrease in 2013 the prevalence of hypertension in Indonesia obtained through measurements at the age of $\geq 18$ years by $25.8 \%[4]$.

Based on data from the Banjarmasin Health Service in 2014 the first visit with cases suffering from hypertension 19,595 people and the second case of hypertension 52,659 people and one of the health centers with the highest cases of hypertension include Cempaka Health Center with the first visit of about 612 people and for the second visit or more around 3,088 person. According to data from the Banjarmasin Cempaka Community Health Center in January-November 2015 there were visits with 820 cases of hypertension and 5.647 cases of old hypertension. For men who suffer from hypertension cases 2,283 people and for cases of hypertension in women 3,366 people. For cases of hypertension at the Cempaka Health Center which suffer a lot of hypertension in women.

There are several measures of hypertension treatment with pharmacological and nonpharmacological means. Treatment of hypertension by means of pharmacology using drugs. While the treatment of hypertension by non-pharmacological ways to reduce blood pressure with a healthy lifestyle and consume natural ingredients such as fruits and vegetables ${ }^{[2]}$. Handling using pharmacology can use other types of antihypertensive drugs is a diuretic, while handling using non-pharmacological in terms of lower prices and is also easy to obtain in the community is very beneficial for lowering blood pressure.

According to a 2013 study by the journal Fidahlni \& Sapardi which examined the influence of watermelon juice on reducing blood pressure, said that one of the fruits that can reduce blood pressure is watermelon. Because there are watermelon content that can reduce blood pressure slowly without side effects that can be detrimental to people who consume watermelon. The content of watermelon is potassium and magnesium which can reduce blood pressure. Watermelon fruit in addition to lowering blood pressure is also used to neutralize blood pressure so that if you consume watermelon fruit will not experience a decrease in blood pressure, so that watermelon is safe for consumption, blood pressure will remain stable ${ }^{[5]}$.

Preliminary study results on December 28, 2015 obtained data from several people who went to the Cempaka Health Center in Banjarmasin with hypertension cases for the second visit or more, from September to November 22 people from the observation that many women came to the Cempaka Health Center with above normal blood pressure. . Based on the above phenomenon the author is interested in taking the title "The role of watermelon juice (citrulus vulgaris rubrum) in the management of hypertension" in the working area of Cempaka Health Center Banjarmasin. The purpose of this study was to analyze the role of watermelon juice in the treatment of hypertension in the work area of Cempaka Health Center.

\section{Research Method}

Research locations in the working area of Cempaka Health Center in 2016. The targets of this study were women who lived in Mawar sub-district with recurrent hypertension for 1 month in December 2015 and had examined themselves at the Cempaka Health Center. In this study, researchers used a descriptive research design by describing the results that were obtained at the time of the study. The target or sample of this study was conducted with 18 
respondents suffering from hypertension who will be given watermelon juice (citrulus vulgaris rubrum) for 10 days on every morning. Respondents of the study carried out blood pressure measurements before being given watermelon juice (citrulus vulgaris rubrum), and the place of research to be carried out was in the working area of Cempaka Banjarmasin health center. Data analysis in this study was analyzed based on data obtained by using statistical calculations, ranging from determining changes in average blood pressure during watermelon juice administration to changes in blood pressure before and after giving watermelon juice by using the exbar formula and the linear regression formula.

\section{Result}

\subsection{Average decrease in blood pressure of Sistole}

Based on research that has been done to 18 respondents suffering from hypertension who consume watermelon juice (citrulus vulgaris rubrum) in the working area of Cempaka Health Center, the following data are obtained:

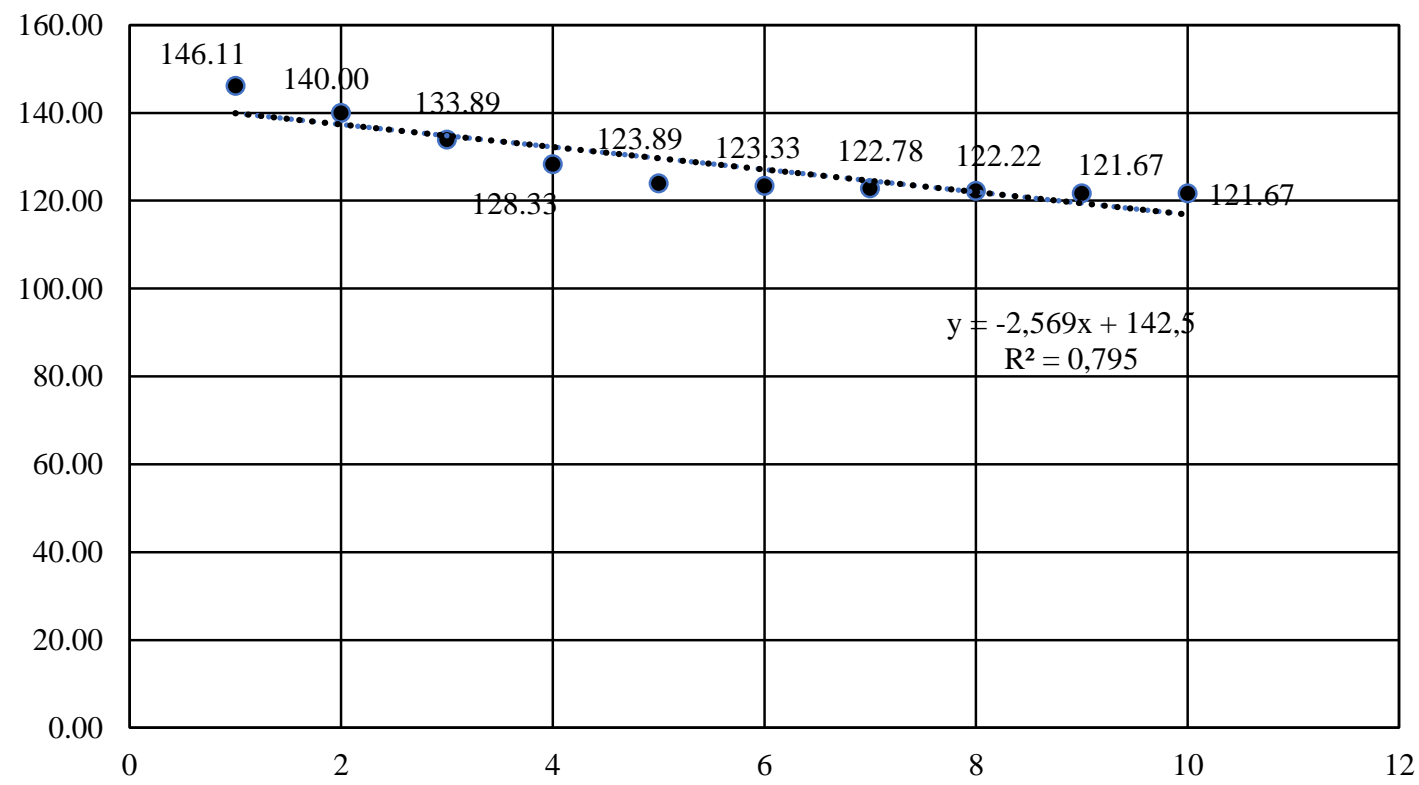

Fig 1. Average Systole Blood Pressure Reduction in the Work Area of Cempaka Health Center 2016

In Figure 1. above shows that the administration of watermelon juice can reduce systole blood pressure starting from day 2 (two) to day 5 (five), this means giving watermelon juice is very instrumental in reducing systole blood pressure. Figure 4.6 
also shows that the stability of blood pressure systole starting from the $6^{\text {th }}$ day to the $10^{\text {th }}$ day during the administration of watermelon juice, this shows that the administration of watermelon juice continuously does not play a role in continuously reducing but can stabilize blood pressure systole.

\subsection{Average decrease in Diastole blood pressure}

Based on research that has been done to 18 respondents suffering from hypertension who consume watermelon juice (citrulus vulgaris rubrum) in the working area of Cempaka Health Center, the following data are obtained:

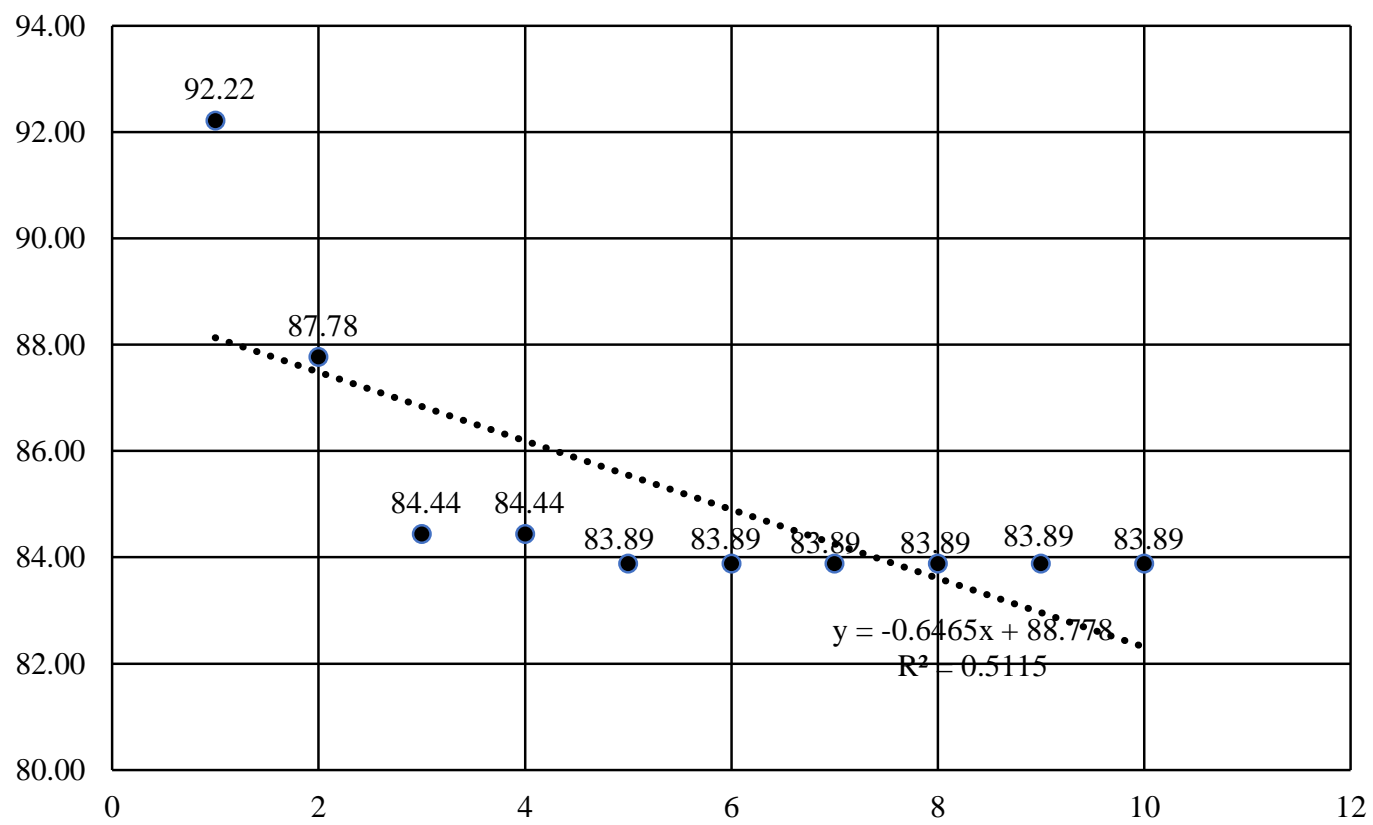

Fig 2. Average Reduction in Diastolic Blood Pressure in the Work Area of Cempaka Health Center 2016

In Figure 2. also shows a similar picture in Figure 4.6, that from the picture shows a decrease in diastolic blood pressure starting on day 2 (two) until the fifth day (five) and diastole blood pressure starting to stabilize from day 6 (six ) until the 10th day (ten) during the administration of watermelon juice.

\section{Discussion}

1. Average changes in blood pressure after being given watermelon juice

a. Average changes in Systolic Blood Pressure 
Based on the research that has been carried out for 10 days for 18 respondents who suffer from hypertension in the working area of the Cempaka Health Center in 2016, the results of the study in Figure 4.6 show that after consuming watermelon juice (citrulus vulgaris rubrum) with an average systole blood pressure 121.67 $\mathrm{mmHg}$ with The standard deviation is $3.83 \mathrm{mmHg}$ which on the 10th day of the respondent after consuming watermelon juice.

Before given watermelon juice (citrulus vulgaris rubrum) food intake consumed by the subject can make an increase in blood pressure and before given watermelon juice (citrulus vulgaris rubrum) to 18 respondents systolic blood pressure above normal. After being given watermelon juice (citrulus vulgaris rubrum) for 10 days there is a decrease in average blood pressure. Before consuming watermelon juice, blood pressure is very high after consuming watermelon juice (citrulus vulgaris rubrum) in 10 days, it has decreased systolic blood pressure. consuming watermelon juice can stimulate urine expenditure because watermelon (citrulus vulgaris rubrum) contains a lot of water so that excess sodium levels in the body can be excreted through urine while high enough potassium content in watermelon (citrulus vulgaris rubrum) can help the heart work and normalize blood pressure and maintain blood pressure in order to remain normal.

When consuming watermelon juice (citrulus vulgaris rubrum) for 10 days, respondents maintain a good diet, not consuming fruits other than watermelon (citrulus vulgaris rubrum). Of the 18 people who became respondents, 10 people who have hereditary factors Hypertension and 8 people due to stress, age, and a bad lifestyle. According to [5]one of the factors that cause hypertension is genetic, age, sex, stress, unhealthy lifestyle, obesity, salt, coffee, cigarettes. According to Pudiastuti, (2013) by consuming watermelon juice can treat hypertension by reducing high blood pressure, which is one of the ingredients in watermelon Potassium and magnesium, a way to increase the intake of potassium and magnesium contained in fruits and reduce high intake of sodium, potassium is needed by the body for nerve function and muscle control as well as blood pressure. Potassium is one of the minerals that maintain fluid and electrolyte balance which has a natriuretic and deuretic effect that increases sodium and fluid expenditure in the body. Diuresis has two meanings, the first shows the addition of the volume of urine produced and the second shows the amount of expenditure dissolved substances and water. The way natural diuresis works is by removing a lot of urine where a lot of sodium is drained, causing more fluid to come out, thereby reducing the pressure in the ducts, as well as decreasing extracellular fluid volume and reducing venous return and, ultimately, the effect of lowering cardiac output resulting in a decrease in blood pressure[6]. The mechanism of potassium in lowering blood pressure is to reduce the production of thromboxane vasoconstrictors and increase the production of callidine vasodilators, resulting in vasodilation of blood vessels. Where the vasodilation of these blood vessels will cause a decrease in peripheral resistance and increase cardiac output[7].

According to research conducted by Francisco Borges (2013) consuming 5day watermelon juice can reduce blood pressure, whereas continued administration of more than 5 days, namely 10 days given watermelon juice can stabilize blood pressure not to lower blood pressure below normal. 
The explanation can be concluded that the potassium and magnesium content in watermelon can reduce blood pressure. The difference in blood pressure before and after being given watermelon juice can be seen in the results of research conducted on patients with hypertension in the working area of Cempaka Health Center 2016.

b. Average change in Diastolic blood pressure

Based on a 10 day study of 18 respondents suffering from hypertension in the working area of the Cempaka Health Center in 2016, the results of the study in Figure 4.7 show that after being given watermelon juice with an average systolic blood pressure of $83.89 \mathrm{mmHg}$ with a standard deviation of $5.01 \mathrm{mmHg}$, which on the 10th day the respondents after consuming watermelon juice (citrulus vulgaris rubrum).

Diastolic blood pressure before being given watermelon juice above normal which is the normal blood pressure limit of Diastole $80-90 \mathrm{mmHg}$ after being given watermelon juice (Citrulus vulgaris rubrum) blood pressure decreased from the second and third days but on the fifth day to the tenth day Diastole blood pressure did not decrease significantly due to diastole blood pressure of the normal respondent that is $80-90 \mathrm{mmHg}$.

Potassium content in watermelon is a mineral that is beneficial to the body. Potassium has a function as a vasodilation in blood vessels can reduce peripheral resistance and increase cardiac output so that blood pressure can be normal. potassium which is high enough and can help the heart work and can normalize blood pressure in systolic and diastolic.

\section{Conclusions}

Total respondents 18 women who suffer from hypertension in the working area of Cempaka Health Center, namely a decrease in blood pressure while given watermelon juice (citrulus vulgaris rubrum) systole with value and the results of the regression coefficient $b=$ 2,569 and the diastole blood pressure regression value $b=-0,511$. The average systolic blood pressure in the respondents after being given watermelon juice (citrulus ?vulgaris rubrum) for 10 days $121.66 \mathrm{mmHg}$, and diastole blood pressure of $83.89 \mathrm{mmHg}$. New findings obtained in this study from previous studies is that a decrease in blood pressure occurs from the first day to the fifth day and blood pressure becomes stable from the sixth to the tenth day, this can indicate that watermelon juice can be recommended for consumed without worrying about uncontrolled drop in blood pressure.

\section{References}

[1] Wahdah, N.: Menaklukan Hipertensi dan Diabetes. Multipres. Yogyakarta (2011)

[2] Junaidi, I.: Hipertensi pengenalan, pencegahan, dan pengobatan. Jakarta: PT Bhuana Ilmu Populer (2010)

[3] WHO.: World Health Day 2013: Measure Your Blood Pressure, Reduce Your Risk. Tersedia dalam: http://www.who.int. [Diakses 16 November 2015.14.30] (2013) 
[4] Rikesdas.: Riset Kesehatan Dasar. [Internet]. From library file//G:/\%C2\%A0/Hasil Rikesdas 2013. pdf. [Di akses 15 November 2013] (2013)

[5] Nisa, I.: Ajaibnya Terapi Herbal Tumpas Penyakit Darah Tinggi. Jakarta : Dunia Sehat (2012)

[6] Pudiastuti, D. R.: Penyakit-Penyakit Mematika.Yogyakarta: Nuha Medika: 16-31 (2013)

[7] Mu J. et al.: Family-based randomized trial to detect effects on blood pressure of a salt substitute containing potassium and calcium in hypertensive adolescents. AMJ. 22(9):943-7. Di unduh pada tanggal

$17 / 11 / 2015$ tersedia

dalam: http://hinarigw.who.int/whalecomwww.ncbi.nlm.nih.gov/whalecom0/pubmed/ terapi jus dan diet $\underline{19661927}(2013)$ 